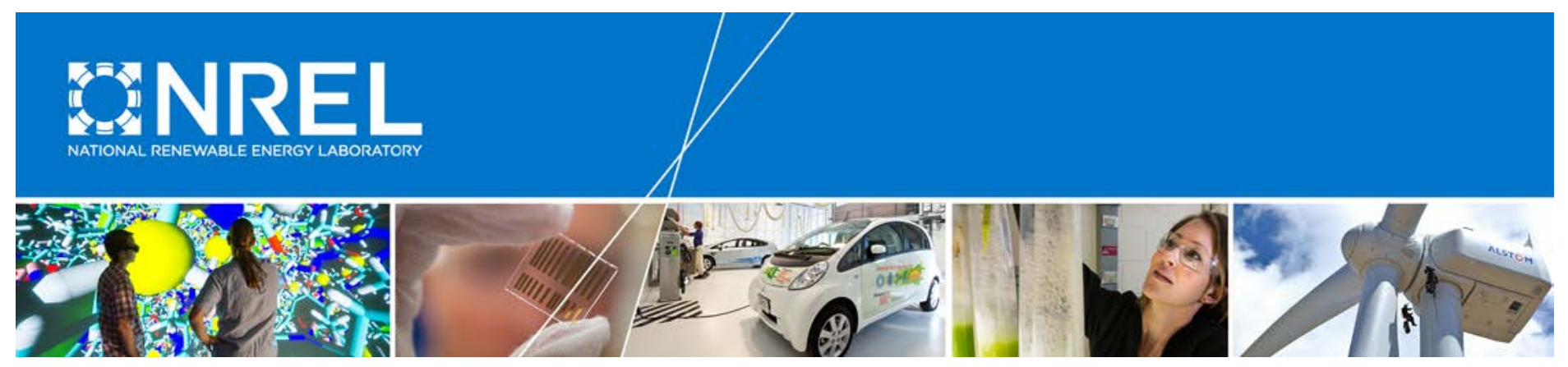

\title{
Characterization of Contact and Bulk Thermal Resistance of Laminations for Electric Machines
}

J. Emily Cousineau, Kevin Bennion, Doug DeVoto, Mark Mihalic, and Sreekant Narumanchi National Renewable Energy Laboratory

NREL is a national laboratory of the U.S. Department of Energy Office of Energy Efficiency \& Renewable Energy Operated by the Alliance for Sustainable Energy, LLC

This report is available at no cost from the National Renewable Energy Laboratory (NREL) at www.nrel.gov/publications.

Technical Report

NREL/TP-5400-63887

June 2015 


\section{Characterization of Contact and Bulk Thermal Resistance of Laminations for Electric Machines}

J. Emily Cousineau, Kevin Bennion, Doug DeVoto, Mark Mihalic, and Sreekant Narumanchi National Renewable Energy Laboratory

Prepared under Task Nos. VTP2.7000 and VTP2.7401

NREL is a national laboratory of the U.S. Department of Energy Office of Energy Efficiency \& Renewable Energy Operated by the Alliance for Sustainable Energy, LLC

This report is available at no cost from the National Renewable Energy Laboratory (NREL) at www.nrel.gov/publications.

National Renewable Energy Laboratory 15013 Denver West Parkway Golden, CO 80401

303-275-3000 • www.nrel.gov

\section{Technical Report}

NREL/TP-5400-63887

June 2015

Contract No. DE-AC36-08G028308 


\title{
NOTICE
}

This report was prepared as an account of work sponsored by an agency of the United States government. Neither the United States government nor any agency thereof, nor any of their employees, makes any warranty, express or implied, or assumes any legal liability or responsibility for the accuracy, completeness, or usefulness of any information, apparatus, product, or process disclosed, or represents that its use would not infringe privately owned rights. Reference herein to any specific commercial product, process, or service by trade name, trademark, manufacturer, or otherwise does not necessarily constitute or imply its endorsement, recommendation, or favoring by the United States government or any agency thereof. The views and opinions of authors expressed herein do not necessarily state or reflect those of the United States government or any agency thereof.

This report is available at no cost from the National Renewable Energy Laboratory (NREL) at www.nrel.gov/publications.

Available electronically at SciTech Connect http:/www.osti.gov/scitech

Available for a processing fee to U.S. Department of Energy and its contractors, in paper, from:

\author{
U.S. Department of Energy \\ Office of Scientific and Technical Information \\ P.O. Box 62 \\ Oak Ridge, TN 37831-0062 \\ OSTI http://www.osti.gov \\ Phone: 865.576.8401 \\ Fax: 865.576.5728 \\ Email: reports@osti.gov
}

Available for sale to the public, in paper, from:

\author{
U.S. Department of Commerce \\ National Technical Information Service \\ 5301 Shawnee Road \\ Alexandra, VA 22312 \\ NTIS http://www.ntis.gov \\ Phone: 800.553 .6847 or 703.605 .6000 \\ Fax: 703.605.6900 \\ Email: orders@ntis.gov
}




\section{Preface}

Thermal management for electric machines is important as the automotive industry continues to transition to more electrically dominant vehicle propulsion systems. With the push to reduce component size, lower costs, and reduce weight without sacrificing performance or reliability, the challenges associated with thermal management for power electronics and electric machines increase. The transition to more electrically dominant propulsion systems leads to higher-power duty cycles for electric drive systems. Thermal management of electric machines directly improves power density and reliability; however, it is a significant challenge because heat transfer and fluid flow in electric machines are complex. Thermal management is one path to improve the performance, efficiency, cost, and the sizing of electric machines to operate within thermal constraints.

During the development of thermal models for electric machines, we found a lack of open literature detailing the thermal properties of key materials common in electric machines that are significant in terms of heat removal. The lack of available literature, coupled with strong interest from industry in the passive-stack thermal measurement results, led to experiments to characterize the thermal properties of motor laminations and the internal lamination-tolamination thermal contact resistance. 


\section{Acknowledgments}

The authors would like to acknowledge the support provided by Susan Rogers and Steven Boyd, Technology Development Managers for the Electric Drive Technologies Program, Vehicle Technologies Office, U.S. Department of Energy Office of Energy Efficiency and Renewable Energy.

We acknowledge the significant contribution from Adam Stokes (National Renewable Energy Laboratory) to the project. We also acknowledge the support, collaboration, and sample motor materials provided by Andrew Wereszczak and Tim Burress (Oak Ridge National Laboratory). 


\section{List of Acronyms}

A

ASTM

ATF

$\mathrm{k}$

$\mathrm{k}_{\text {eff }}$

$\mathrm{k}_{\mathrm{L}}$

$\mathrm{m}$

$\mathrm{N}_{\mathrm{C}}$

$\mathrm{N}_{\mathrm{L}}$

NREL

$\mathrm{R}_{\mathrm{C}}$

$\mathrm{R}_{\mathrm{G}}$

$\mathrm{R}_{\mathrm{L}}$

$\mathrm{R}_{\text {th }}$

$\mathrm{SF}$

$\mathrm{t}$

$\mathrm{U}_{95}$ geometric area

ASTM International

automatic transmission fluid

thermal conductivity

effective thermal conductivity

bulk thermal conductivity of lamination material

first-order slope

number of contacts

number of laminations (defined as $\mathrm{N}_{\mathrm{C}}+1$ )

National Renewable Energy Laboratory

thermal contact resistance

thermal resistance of grease layer

thermal resistance of one lamination

thermal resistance

stacking factor

thickness of a single lamination

$95 \%$ confidence interval 


\section{Executive Summary}

The ability to remove heat from an electric machine depends on the passive stack thermal resistances within the machine and the convective cooling performance of the selected cooling technology. This report focuses on the passive thermal design, specifically properties of the stator and rotor lamination stacks. Orthotropic thermal conductivity, specific heat, and density are reported. Four materials commonly used in electric machines were tested, including M19 (29 and 26 gauge), HF10, and Arnon 7 materials.

All measurements for effective through-stack thermal conductivity used a custom-built setup at the National Renewable Energy Laboratory built in accordance with ASTM International Standard D5470-12 for measuring direction-dependent thermal conductivity of materials. Lamination properties were measured along the plane of the laminations and perpendicular to the laminations or through a stack of laminations. For measurement of through-stack thermal conductivity, data from different stack heights were measured and fitted to a weighted curve fit. This method allowed a measurement of bulk thermal conductivity independent of stack thickness and interface resistances within the test setup. Bulk thermal conductivity, specific heat, and density were tested using commercially available equipment.

Lamination-to-lamination contact resistance is a key factor in the effective through-stack thermal conductivity. Clamping pressure and surface finish affect the thermal contact resistance. The thickness of laminations can also influence effective through-stack thermal conductivity. Effective material property results for the four materials are summarized, including 95\% confidence intervals.

Property data are provided to aid in development of steady state and transient thermal finite element analysis models for electric machines. Information and equations used to calculate through-stack thermal conductivity are also provided. The work fills a current need for material property data specific to electric machine design that currently does not exist in public literature. Although this report focuses on electric machines for electric-drive vehicle applications, the results are applicable to any electric machine where low thermal resistance and efficient heat removal are important to increasing machine performance and power density. 


\section{Table of Contents}

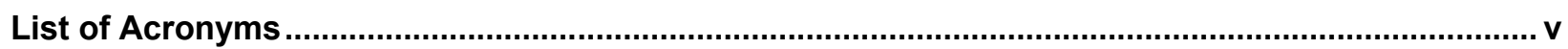

Executive Summary ....................................................................................................................... vi

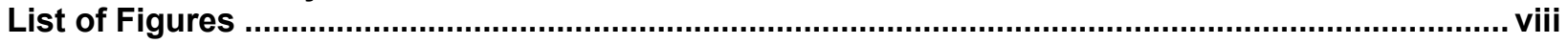

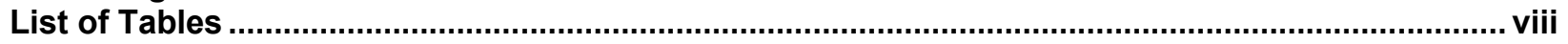

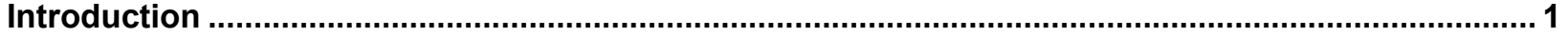

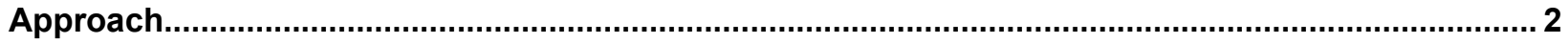

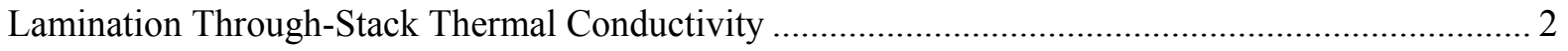

Lamination In-Plane Thermal Conductivity .................................................................. 5

Lamination Bulk Properties..................................................................................... 5

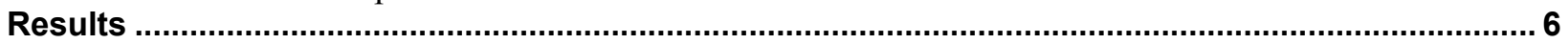

Lamination Through-Stack Thermal Conductivity ............................................................ 6

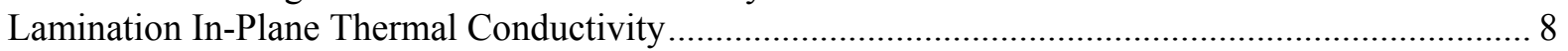

Summary of Lamination Properties............................................................................... 10

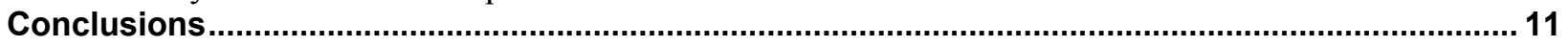

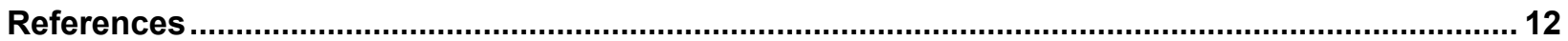




\section{List of Figures}

Figure 1. Electric machine cross-section showing several possible cooling scenarios............................... 1

Figure 2. Orthotropic thermal property orientation for motor laminations. Through-stack conductivity is along the $\mathrm{z}$-axis, and in-plane thermal conductivity is along the $\mathrm{x}-\mathrm{y}$ plane. ............................ 2

Figure 3. Schematic (left) and photo (right) of steady-state setup for measuring orthotropic thermal conductivity values (photo credit: Emily Cousineau, NREL) ............................................... 3

Figure 4. Equation 4 plotted against the number of laminations compared to Equation 5, which represents

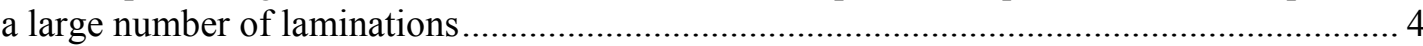

Figure 5. Test setup for measuring in-plane lamination thermal conductivity (photo credit: Emily Cousineau, NREL)

Figure 6. M19 29-guage $138 \mathrm{kPa}$ data set with weighted curve fit. Error bars represent systematic standard error.

Figure 7. Summary of measured interlamination contact resistance for materials tested at the four pressures. Error bars represent a $\mathrm{U}_{95}$ confidence interval. ................................................. 6

Figure 8. Interlamination thermal contact resistances shown with averages of smooth samples and

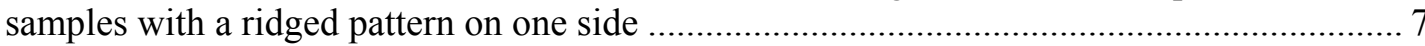

Figure 9. Scanning electron microscope images of M19, 29-gauge material (photo credit: Adam Stokes,

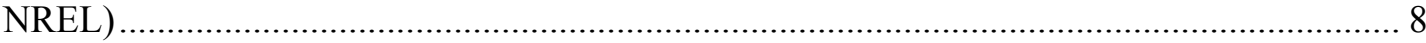

Figure 10. Effective through-stack thermal conductivity for lamination stacks. Error bars represent a $\mathrm{U}_{95}$

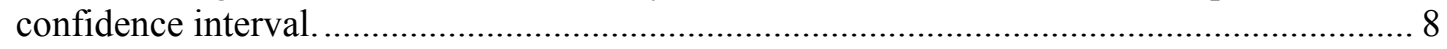

Figure 11. Comparison of bulk lamination thermal conductivity, estimated in-plane thermal conductivity assuming a 99\% stacking factor, and in-plane thermal conductivity for M19 29-gauge laminations was measured with the ASTM test apparatus

\section{List of Tables}

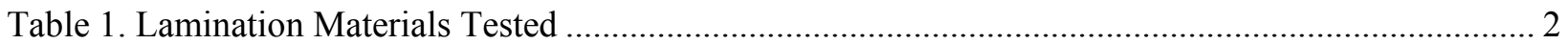

Table 2. M19, 26-Gauge Properties with $\mathrm{U}_{95}$ Confidence Interval Where Applicable.............................. 10

Table 3. M19, 29-Gauge Properties with $\mathrm{U}_{95}$ Confidence Interval Where Applicable.............................. 10

Table 4. HF10 Properties with $\mathrm{U}_{95}$ Confidence Interval Where Applicable ............................................ 10

Table 5. Arnon 7 Properties with $\mathrm{U}_{95}$ Confidence Interval Where Applicable....................................... 10 


\section{Introduction}

The ability to remove heat from an electric machine depends on the passive stack thermal resistances within the machine and the convective cooling performance of the selected cooling technology. The passive thermal design refers to the geometrical layout, material selection, and thermal interfaces that affect the heat-spreading capabilities within the motor. The ability for heat to spread through the motor affects the thermal temperature gradients within the motor. The active convective cooling technology is the cooling mechanism that ultimately removes the heat from the motor and transfers the heat to another location to reject the heat to the ambient environment. Figure 1 shows a sample cross-section schematic of an electric machine detailing components and example cooling methods, including a water jacket and several types of automatic transmission fluid (ATF) cooling methods.

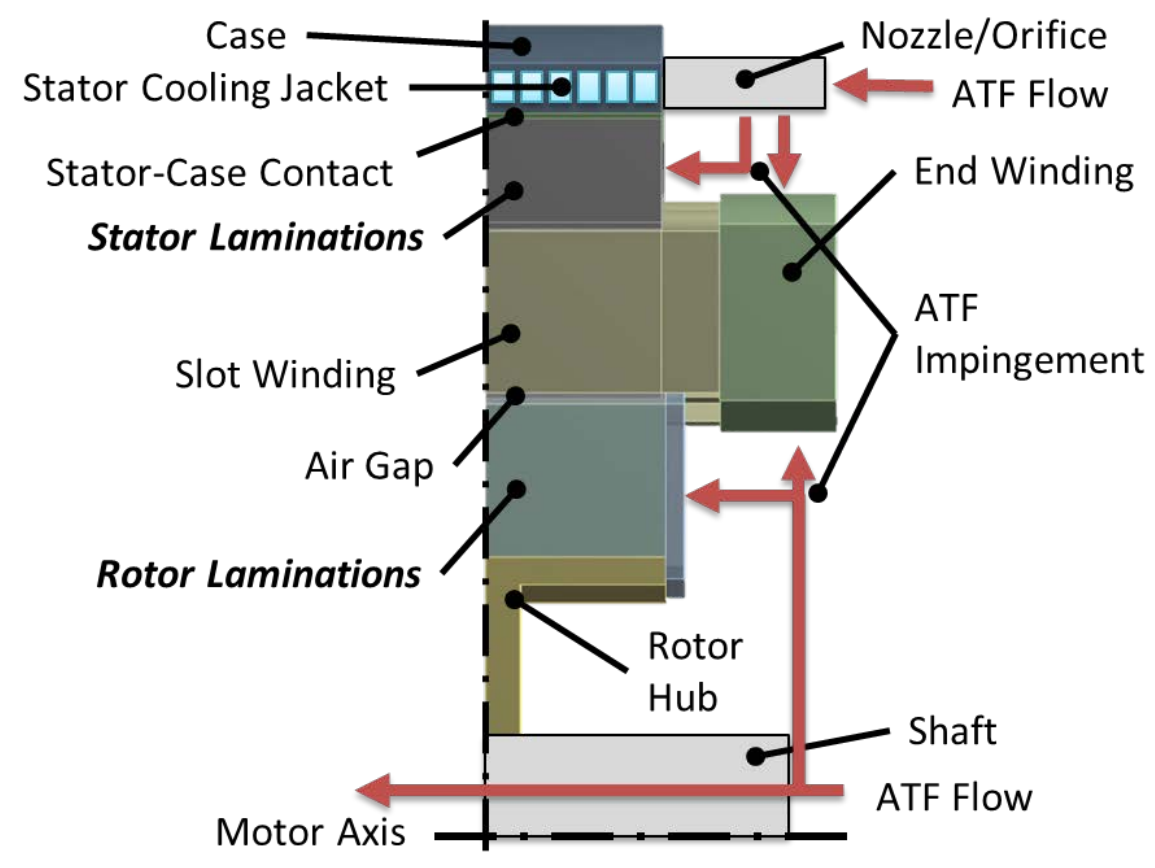

Figure 1. Electric machine cross-section showing several possible cooling scenarios

This investigation focuses on the passive thermal design, specifically properties of the stator and rotor lamination stacks. The lamination stacks are a significant portion of the thermal pathway for removing heat from the motor [1]. The effective thermal conductivity of the lamination stack is orthotropic, as shown in Figure 2. Thus, it is important to determine effective properties for both in-plane (shown in Figure 2 as the $\mathrm{x}-\mathrm{y}$ plane) and through-stack (shown in Figure 2 as the $\mathrm{z}$ direction). The thermal conductivity of the base material (bulk thermal conductivity), specific heat, and density are also reported. 


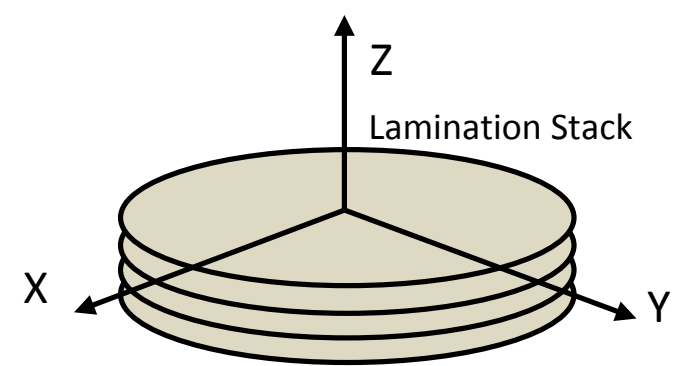

Figure 2. Orthotropic thermal property orientation for motor laminations. Through-stack conductivity is along the z-axis, and in-plane thermal conductivity is along the $x-y$ plane.

Researchers at the National Renewable Energy Laboratory (NREL) experimentally measured effective thermal properties and lamination-to-lamination or interlamination contact resistance of different types of commonly used stator laminations. The information was used to calculate the effective through-stack thermal conductivity of the lamination materials. Such nonbiased and consistent information is not available in the open literature. The data compare a range of lamination materials, detailed in Table 1, and demonstrate how the interlamination contact pressure and surface profile of lamination materials in contact affect the lamination-tolamination thermal contact resistance.

Table 1. Lamination Materials Tested

\begin{tabular}{lll}
\hline Material & Thickness $(\mathbf{m m})$ & Notes \\
\hline M19 & 0.470 & 26 gauge \\
M19 & 0.356 & 29 gauge \\
HF10 & 0.254 & \\
Arnon 7 & 0.178 & \\
\hline
\end{tabular}

The M19 materials were tested because they are commonly used in electric machines. HF10 and Arnon 7 are thinner materials that reduce eddy currents responsible for core losses versus the M19 [2]. All lamination materials had a C-5 coating on one side to provide electrical resistance against formation of eddy currents.

\section{Approach}

\section{Lamination Through-Stack Thermal Conductivity}

Figure 3 shows the setup that was used to measure effective through-stack thermal conductivity. The test apparatus was built in accordance with ASTM Standard D5470-12 steady-state technique [3,4]. The advantage of this setup for this application is it sets up a one-dimensional heat flux and therefore enables measurement of thermal properties in one specific direction and independent of other directions. 

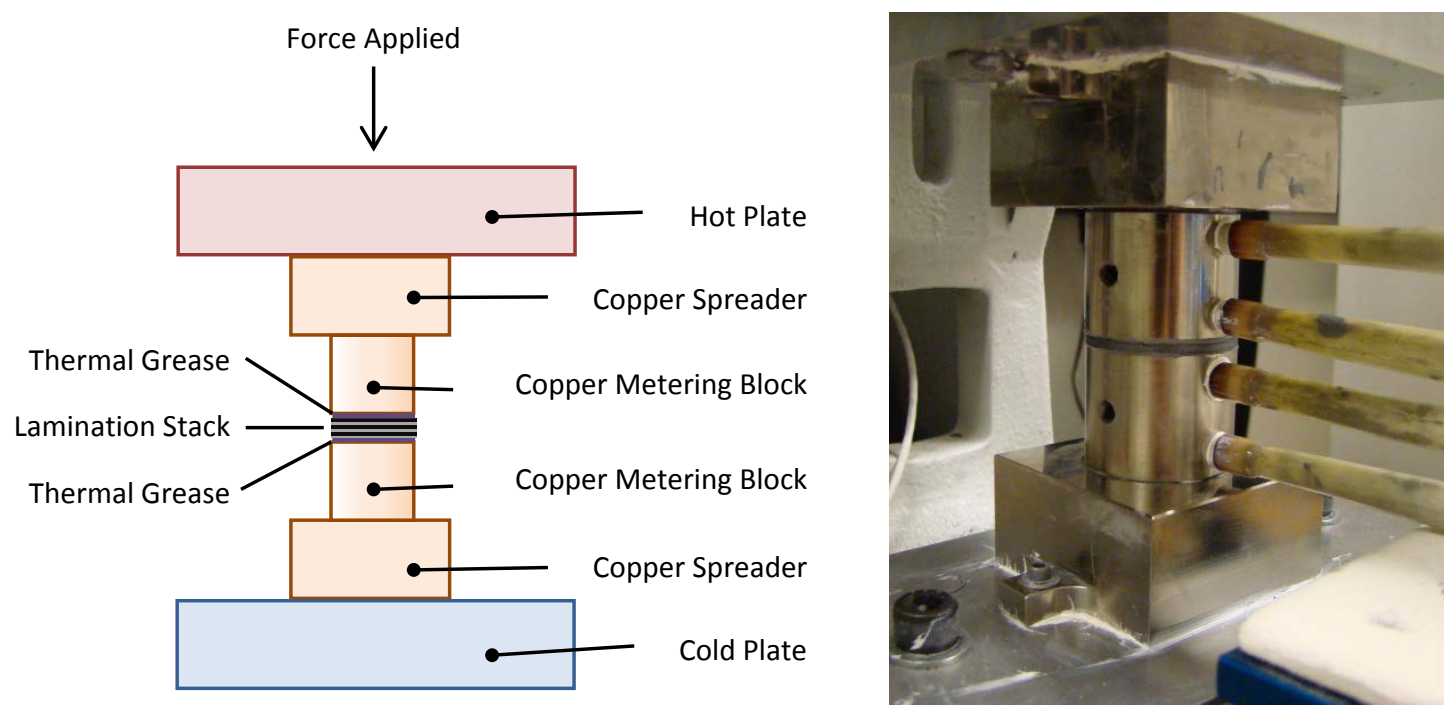

Figure 3. Schematic (left) and photo (right) of steady-state setup for measuring orthotropic thermal conductivity values (photo credit: Emily Cousineau, NREL)

Each test was performed at four pressures: 138, 276, 414, and $552 \mathrm{kPa}(20,40,60$, and $80 \mathrm{psi}$, respectively). These pressures were based on industry feedback and equipment limitations. The total thermal resistance $\left(\mathrm{R}_{\mathrm{th}}\right)$ of the stack measured by the ASTM setup can be broken down analytically. As shown in Equation 1, $\mathrm{R}_{\mathrm{L}}$ is the thermal resistance of a single lamination. $\mathrm{R}_{\mathrm{C}}$ is the thermal contact resistance between two laminations. $\mathrm{N}_{\mathrm{C}}$ is the number of lamination-tolamination contacts in the stack, and $\mathrm{R}_{\mathrm{G}}$ is the thermal resistance of each grease layer.

$$
R_{t h}\left(N_{C}\right)=\left(R_{C}+R_{L}\right) N_{C}+R_{L}+2 R_{G}
$$

As shown in Equation 1, $\mathrm{R}_{\mathrm{th}}$ is a function of $\mathrm{N}_{\mathrm{C}}$. As a result, by measuring different stack heights and fitting to a slope, $\mathrm{m}$, any constant resistance present, such as $\mathrm{R}_{\mathrm{G}}$, can be eliminated as shown in Equation 2.

$$
\frac{d}{d N_{C}}\left(\left(R_{C}+R_{L}\right) N_{C}+R_{L}+R_{G}\right)=R_{C}+R_{L}=m
$$

The number of laminations $\left(\mathrm{N}_{\mathrm{L}}\right)$ in the stack is always one more than the number of contacts (Equation 3). Because the number of laminations does not equal the number of interlamination contacts in a stack, the thermal conductivity of the stack is inhomogeneously length dependent, as shown in Equation 4, where $t$ is the thickness of an individual lamination. However, as shown in Figure 4, as the stack height increases, the relative difference between the number of laminations and number of contacts approaches unity and approaches the effective thermal conductivity $\left(\mathrm{k}_{\mathrm{eff}}\right)$ asymptotically as shown in Equation 5. Equation 6 shows alternative formulations that can be derived from Equations 1 through 4, with $\mathrm{k}_{\mathrm{L}}$ being the thermal conductivity of the bulk lamination material.

$$
N_{L} \equiv N_{C}+1
$$




$$
\begin{gathered}
k=\frac{\text { Total Thickness }}{\text { Total Resistance }}=\frac{t \cdot N_{L}}{R_{C} N_{C}+R_{L} N_{L}} \\
\lim _{N_{C} \rightarrow N_{L}} k=\frac{t}{R_{C}+R_{L}} \\
k_{\text {eff }}=\frac{t}{R_{C}+R_{L}}=\left(\frac{R_{C}}{t}+\frac{1}{k_{L}}\right)^{-1}=t / m
\end{gathered}
$$

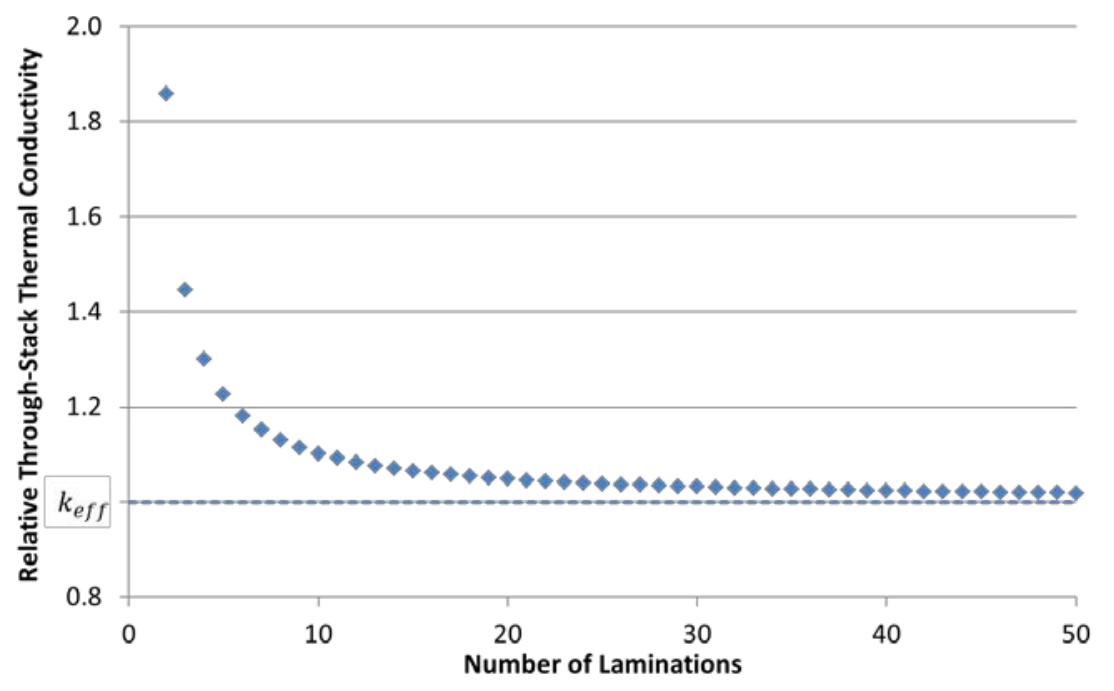

Figure 4. Equation 4 plotted against the number of laminations compared to Equation 5, which represents a large number of laminations

Thermal resistance data from the different stack heights were fitted using a weighted curve fit [5]. Weighting was based on the systematic uncertainty in the measurements, which was found to be proportional to the stack height. The weighted curve-fitting method also captured random uncertainty in the measurements. After the slope of the curve fit was calculated, it was possible to calculate the lamination-to-lamination thermal contact resistance using Equation 2 and the bulk thermal conductivity measured from the xenon flash as shown in Equation 7. Equations in published literature [6] for low-pressure contacts provided confirmation of the measured results.

$$
R_{C}=m-\frac{t}{k_{L}}
$$

Performing five repetitions at each stack height provided the data to quantify random uncertainty. Three stack heights were measured for each material (two, five, and eight laminations), except for the M19 29-gauge material, for which seven stack heights were tested initially. Using seven stack heights provided seven data points for the curve fit. The seven point fit was compared to a three point fit to confirm that three points would be sufficient to fit the data in order to reduce the number of experiments required. It is documented in literature that contact thermal resistance will reduce with load cycling and thermal cycling [7]. Therefore, only the first loading cycle was considered. The $95 \%$ confidence interval $\left(\mathrm{U}_{95}\right)$ was calculated for the results following established practices [8]. 


\section{Lamination In-Plane Thermal Conductivity}

Although the through-stack thermal conductivity measurements were the primary focus of the lamination measurements, the effective in-plane thermal conductivity of a lamination stack was measured in collaboration with Oak Ridge National Laboratory. Lamination-to-lamination contact resistance is not a factor for in-plane thermal conductivity. Because the material is homogeneous in-plane, an area-weighted method as shown in Equation 8 can be applied to determine the effective in-plane thermal conductivity [9].

$$
k_{\text {eff }}=k_{L} \frac{A_{L}}{A_{\text {total }}}+k_{\text {coat }} \frac{A_{\text {coat }}}{A_{\text {total }}}+k_{\text {air }} \frac{A_{\text {air }}}{A_{\text {total }}}
$$

where $L$ is the bulk material, coat is the lamination coating, and air is the interstitial airspace between the laminations. It was found experimentally that the fill factor exceeds $99 \%$ for pressures of $20 \mathrm{kPa}$ or above, indicating that the coating and air make a trivial contribution to the in-plane thermal conductivity. The same ASTM setup used to measure through-stack thermal conductivity was used to measure in-plane thermal conductivity, as shown in Figure 5. Oak Ridge National Laboratory prepared the sample. Square metering blocks were used instead of cylindrical metering blocks to accommodate the shape of the sample coupon.

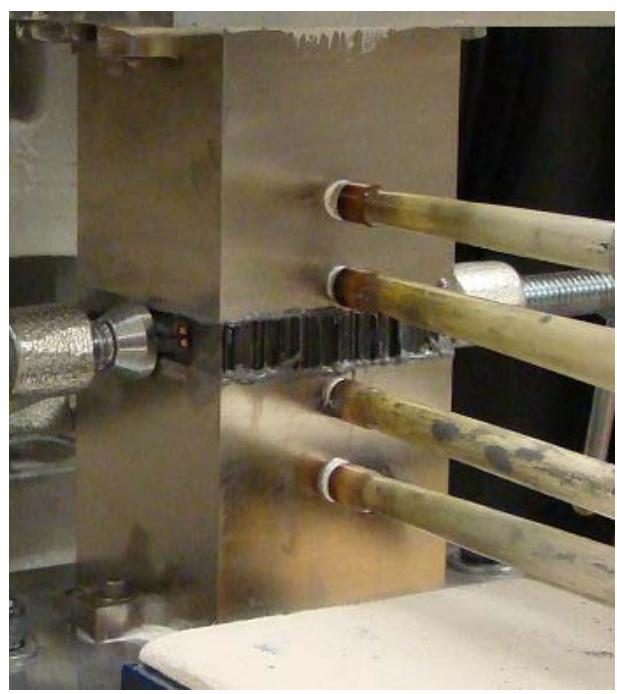

Figure 5. Test setup for measuring in-plane lamination thermal conductivity (photo credit: Emily Cousineau, NREL)

\section{Lamination Bulk Properties}

Bulk properties of the lamination material were also measured. Bulk thermal conductivity was measured using a xenon flash transient technique. Knowing the bulk thermal conductivity allows the contact resistance to be determined from Equation 7. Specific heat was measured using a differential scanning calorimeter. Density was measured by dividing the weight of the sample by volume and taking the average of 10 samples. 


\section{Results}

\section{Lamination Through-Stack Thermal Conductivity}

As shown in Equation 6, the through-stack thermal conductivity is a function of the lamination thickness and the curve fit slope from measuring different stack heights. Figure 6 shows an example fit for the M19 29-gauge lamination material. Error bars indicate the systematic standard error. Each stack height was measured five times to determine random error, which was captured during the curve fit process.

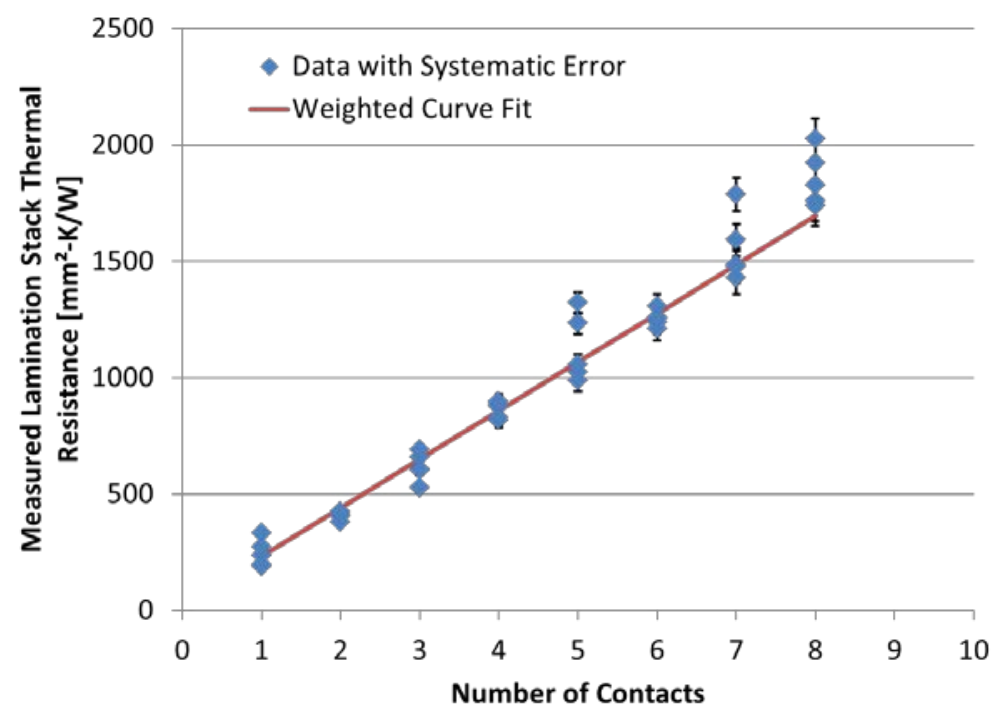

Figure 6. M19 29-guage $138 \mathrm{kPa}$ data set with weighted curve fit. Error bars represent systematic standard error.

The ASTM measurements yield the curve fit slope (m), and the xenon flash measurements provide lamination thermal resistance $\left(\mathrm{R}_{\mathrm{L}}\right)$. The two terms substituted into Equation 2 give the interlamination thermal contact resistance $\left(\mathrm{R}_{\mathrm{C}}\right)$. Figure 7 shows the results.

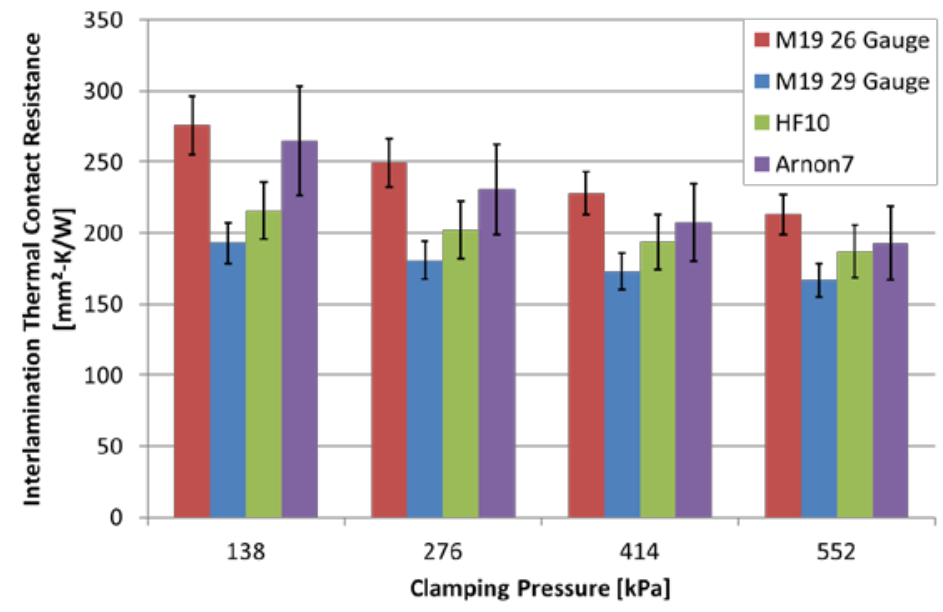

Figure 7. Summary of measured interlamination contact resistance for materials tested at the four pressures. Error bars represent a $U_{95}$ confidence interval. 
The M19 29-gauge and HF10 materials both had a small ridged pattern on one side, which was assumed to be from the manufacturing process. These patterns were not present on the M19 26gauge or Arnon 7 materials. When the interlamination contact resistance is plotted with ridged and smooth averages, shown in Figure 8, it is clear that the different surfaces follow two distinct trends. Depending on the clamping pressure, the ridges decrease interlamination contact resistance by $13 \%$ to $24 \%$ with respect to the smooth contacts. The general decrease in pressure dependence is due to the ridges fixing the number of microscopic contact points between laminations. The smooth surfaces vary the number of microscopic contact points with changes in pressure. The lower overall thermal resistance is due to each contact point in the ridged pattern being at higher pressure. As the pressure increases, the advantage of the ridged surface over the smooth surface is reduced as the number of microscopic contacts becomes equal between the two surface types. There is also a weak positive correlation between contact resistance and surface roughness, which is apparent in Figure 8. The samples' average surface roughness ranged from 0.84 to $1.43 \mu \mathrm{m}$.

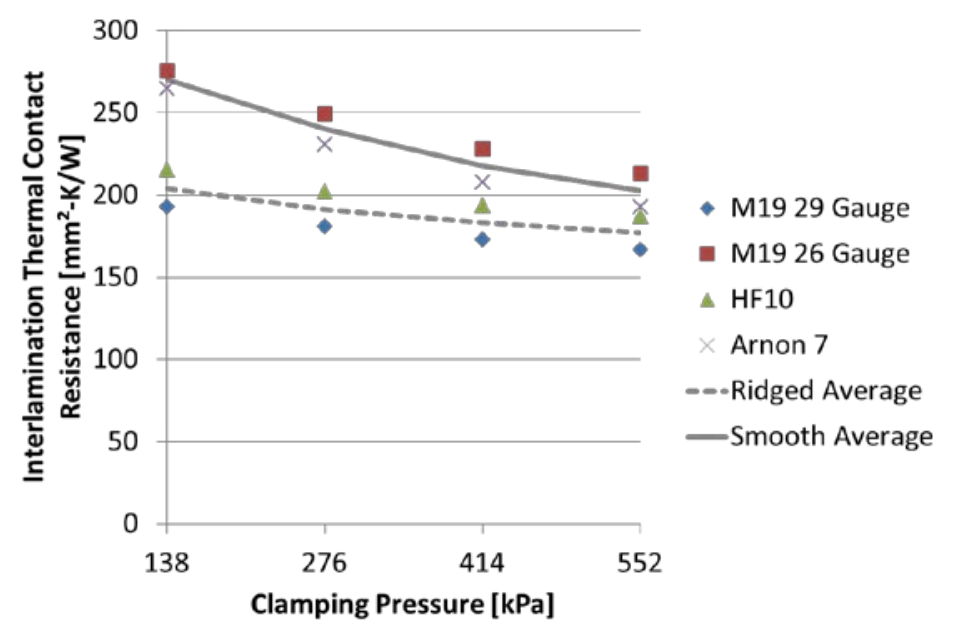

Figure 8. Interlamination thermal contact resistances shown with averages of smooth samples and samples with a ridged pattern on one side

The C-5 coating is included in the contact resistance measurement, but its precise effect and variation in thermal performance between samples is not certain. C-5 coatings contain inorganic compounds and ceramic fillers to maximize electrical insulation. However, ASTM Standard A976-13 only requires a set of electrical and durability characteristics to be met [10]. Thermal properties (except durability requirements) and materials used are not defined. For the materials tested, the presence of a C-5 coating was confirmed with an electrical conductivity test. The images in figure 9 were generated with a scanning electron microscope technique, using a focused ion beam to cut the material. The focused ion beam technique creates an undistorted cross section, facilitating accurate measurement of the coating. On three of the four samples, a 2$\mu \mathrm{m}$ coating was present on one side only. The exception was the M19, 26-gauge material. For the M19 26-gauge material, it was not possible to distinguish visually the C5 coating from the lamination to measure thickness. 


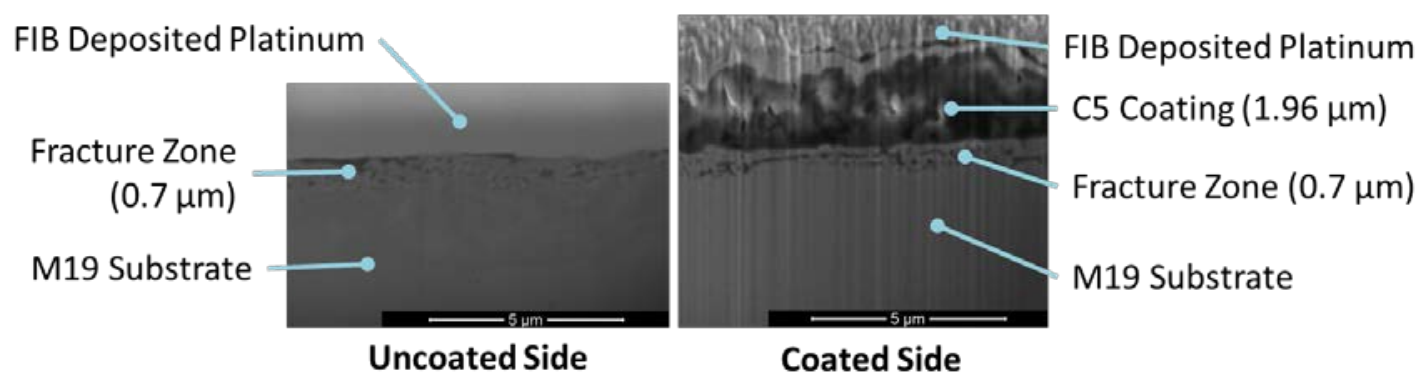

Figure 9. Scanning electron microscope images of M19, 29-gauge material (photo credit: Adam Stokes, NREL)

Figure 10 shows the effective through-stack thermal conductivity for each of the tested lamination materials. The through-stack thermal conductivity was calculated using Equation 6 using data from the curve fit slope shown in Figure 6 and the measured single lamination thickness. The interlamination thermal contact resistance is a substantial thermal barrier compared to the bulk resistance of the material. Therefore, as implied by Equation 6, thinner lamination materials have lower effective through-stack thermal conductivity because there are more contacts per unit length. The apparent discrepancy of the 29 gauge thermal conductivity exceeding the 26 gauge's at low clamping pressure may be due to the ridged pattern on the 29 gauge material surface facilitating the thermal contact. The effect is not observed at higher pressures.

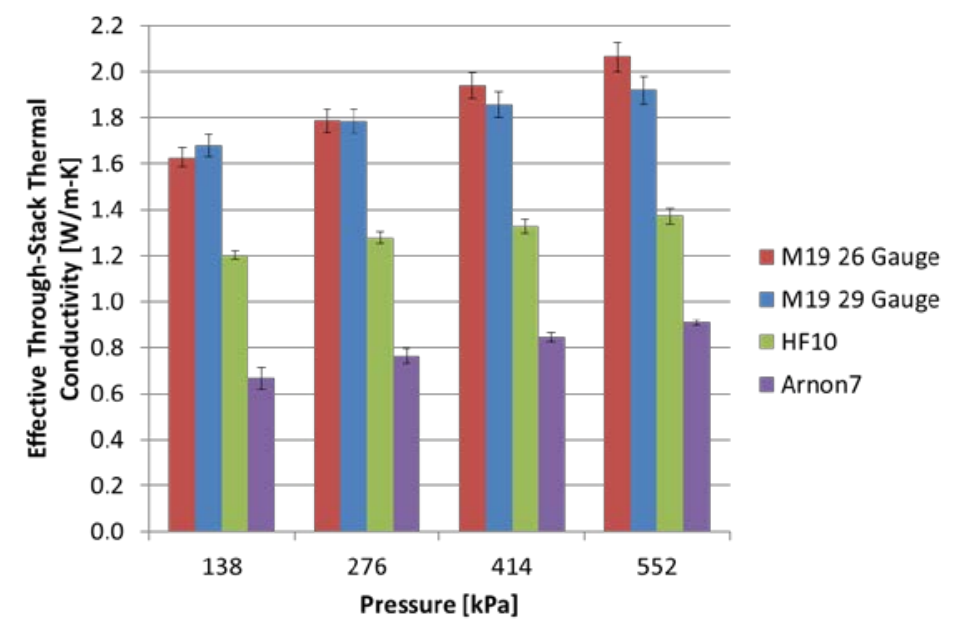

Figure 10. Effective through-stack thermal conductivity for lamination stacks. Error bars represent a $U_{95}$ confidence interval.

\section{Lamination In-Plane Thermal Conductivity}

The estimate of in-plane thermal conductivity was based on Equation 8. It was conservatively estimated that the stacking factor (SF) would be at least $99 \%$ and the interlamination air gaps simplified as vacuum (perfect thermal insulator) reducing to Equation 9

$$
k_{\text {eff in-plane }} \approx S F \cdot k_{\text {bulk }}
$$


Figure 11 compares the bulk material thermal conductivity with the in-plane estimate and value measured using the setup shown in Figure 5. The random uncertainty in the measurements for the bulk material thermal conductivity measured on xenon flash was $\pm 0.05 \mathrm{~W} / \mathrm{m}-\mathrm{K}$. The random uncertainty for the test apparatus was $\pm 0.3 \mathrm{~W} / \mathrm{m}-\mathrm{K}$. Taking into account random error and systematic error, the $95 \%$ confidence interval $\left(\mathrm{U}_{95}\right)$ was $\pm 1.38 \mathrm{~W} / \mathrm{m}-\mathrm{K}$. There was no significant difference between the bulk, estimated, and measured values, indicating there are no unanticipated effects in-plane due to the stack up.

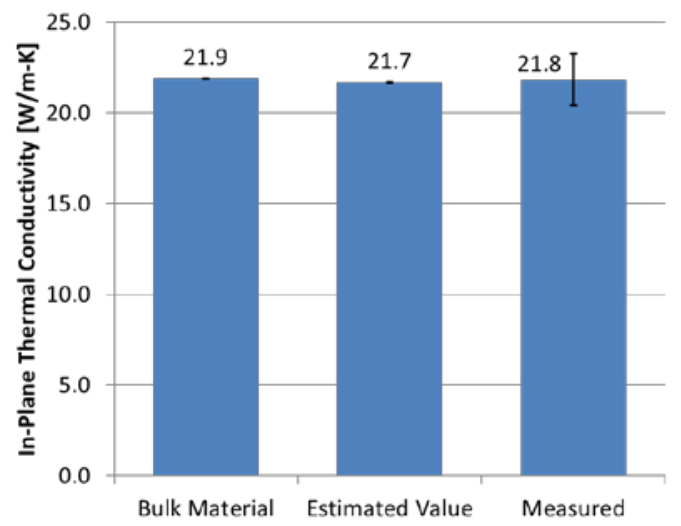

Figure 11. Comparison of bulk lamination thermal conductivity, estimated in-plane thermal conductivity assuming a $99 \%$ stacking factor, and in-plane thermal conductivity for M19 29-gauge laminations was measured with the ASTM test apparatus 


\section{Summary of Lamination Properties}

Based on the results, in-plane thermal conductivity is given as bulk thermal conductivity.

Density and specific heat cannot be anisotropic and it is assumed there is no difference between bulk properties and effective stack properties based on the measured stacking factors. Table 2 through Table 5 give the properties of each lamination material tested.

Table 2. M19, 26-Gauge Properties with $U_{95}$ Confidence Interval Where Applicable

\begin{tabular}{lllll}
\hline Property & $\mathbf{1 3 8} \mathbf{~ k P a}$ & $\mathbf{2 7 6} \mathbf{~ k P a}$ & $\mathbf{4 1 4} \mathbf{~ k P a}$ & $\mathbf{5 5 2} \mathbf{~ k P a}$ \\
\hline Through-stack Effective Thermal Conductivity [W/m-K] & $1.63 \pm 0.04$ & $1.79 \pm 0.05$ & $1.94 \pm 0.06$ & $2.07 \pm 0.06$ \\
Measured Contact Resistance [mm²-K/W] & $276 \pm 20$ & $249 \pm 17$ & $228 \pm 15$ & $213 \pm 14$ \\
\hline In-plane/Bulk Thermal Conductivity $[\mathrm{W} / \mathrm{m}-\mathrm{K}]$ & & \multicolumn{2}{c}{23.0} \\
Density $\left[\mathrm{kg} / \mathrm{m}^{3}\right]$ & & \multicolumn{2}{c}{7,300} \\
Specific Heat $[\mathrm{J} / \mathrm{kg}-\mathrm{K}]$ & & 451 & \\
\hline
\end{tabular}

Table 3. M19, 29-Gauge Properties with $U_{95}$ Confidence Interval Where Applicable

\begin{tabular}{lllll}
\hline Property & $\mathbf{1 3 8} \mathbf{~ k P a}$ & $\mathbf{2 7 6} \mathbf{~ k P a}$ & $\mathbf{4 1 4} \mathbf{~ k P a}$ & $\mathbf{5 5 2} \mathbf{~} \mathbf{P a}$ \\
\hline Through-stack Effective Thermal Conductivity $[\mathrm{W} / \mathrm{m}-\mathrm{K}]$ & $1.68 \pm 0.05$ & $1.78 \pm 0.05$ & $1.85 \pm 0.06$ & $1.92 \pm 0.06$ \\
Measured Contact Resistance $\left[\mathrm{mm}^{2}-\mathrm{K} / \mathrm{W}\right]$ & $193 \pm 14$ & $181 \pm 13$ & $173 \pm 12$ & $167 \pm 12$ \\
\hline In-plane/Bulk Thermal Conductivity $[\mathrm{W} / \mathrm{m}-\mathrm{K}]$ & & \multicolumn{2}{c}{21.9} \\
Density $\left[\mathrm{kg} / \mathrm{m}^{3}\right]$ & & \multicolumn{2}{c}{7,450} \\
Specific Heat $[\mathrm{J} / \mathrm{kg}-\mathrm{K}]$ & & \multicolumn{2}{c}{463} \\
\hline
\end{tabular}

Table 4. HF10 Properties with $\mathrm{U}_{95}$ Confidence Interval Where Applicable

\begin{tabular}{|c|c|c|c|c|}
\hline Property & $138 \mathrm{kPa}$ & $276 \mathrm{kPa}$ & $414 \mathrm{kPa}$ & $552 \mathrm{kPa}$ \\
\hline Through-stack Effective Thermal Conductivity [W/m-K] & $1.20 \pm 0.02$ & $1.28 \pm 0.03$ & $1.33 \pm 0.03$ & $1.37 \pm 0.03$ \\
\hline Measured Contact Resistance [mm²-K/W] & $216 \pm 20$ & $202 \pm 20$ & $194 \pm 19$ & $187 \pm 18$ \\
\hline In-plane/Bulk Thermal Conductivity [W/m-K] & \multicolumn{4}{|c|}{20.6} \\
\hline Density $\left[\mathrm{kg} / \mathrm{m}^{3}\right]$ & \multicolumn{4}{|c|}{7,180} \\
\hline Specific Heat $[\mathrm{J} / \mathrm{kg}-\mathrm{K}]$ & \multicolumn{4}{|c|}{456} \\
\hline
\end{tabular}

Table 5. Arnon 7 Properties with $U_{95}$ Confidence Interval Where Applicable

\begin{tabular}{|c|c|c|c|c|}
\hline Property & $138 \mathrm{kPa}$ & $276 \mathrm{kPa}$ & $414 \mathrm{kPa}$ & $552 \mathrm{kPa}$ \\
\hline Through-stack Effective Thermal Conductivity [W/m-K] & $0.67 \pm 0.05$ & $0.76 \pm 0.03$ & $0.85 \pm 0.02$ & $0.91 \pm 0.01$ \\
\hline Measured Contact Resistance $\left[\mathrm{mm}^{2}-\mathrm{K} / \mathrm{W}\right]$ & $265 \pm 38$ & $231 \pm 32$ & $208 \pm 27$ & $193 \pm 26$ \\
\hline In-plane/Bulk Thermal Conductivity [W/m-K] & \multicolumn{4}{|c|}{22.4} \\
\hline Density $\left[\mathrm{kg} / \mathrm{m}^{3}\right]$ & \multicolumn{4}{|c|}{7,190} \\
\hline Specific Heat $[\mathrm{J} / \mathrm{kg}-\mathrm{K}]$ & \multicolumn{4}{|c|}{504} \\
\hline
\end{tabular}




\section{Conclusions}

We provided property data for four lamination materials commonly used in electric machines: M19 (29 and 26 gauge), HF10, and Arnon 7. Orthotropic thermal conductivity, density, and specific heat were measured for each material, providing data relevant to both steady state and transient thermal analysis. Equations used to calculate through-stack thermal conductivity were provided. There are three important conclusions in regards to the orthotropic thermal conductivity:

- Through-stack thermal conductivity is a function of lamination-to-lamination thermal contact resistance, lamination thickness, and bulk thermal conductivity.

- Lamination-to-lamination thermal contact resistance is a function of pressure and surface topography. The samples with the ridged pattern had less dependence on pressure and lower overall thermal contact resistance.

- For any practical application, it is reasonable to assume that the effective in-plane thermal conductivity is the same as the bulk material properties.

These results fill a current need for material property data specific to electric machine design that currently does not exist in public literature. The data provide a range of lamination-to-lamination thermal contact resistance values and equations that can be utilized to estimate effective thermal conductivity for materials not covered in this report. We developed a procedure that is suitable to characterize other materials of interest. The data quantify the difficulty in extracting heat axially through the lamination materials within the motor, which has significant impacts, especially for cooling rotors used in permanent magnet machines. 


\section{References}

[1] Bennion, K., and Cousineau, J., "Sensitivity Analysis of Traction Drive Motor Cooling." Paper presented at the IEEE Transportation Electrification Conference and expo, Dearborn, Michigan, June 18-20, 2012.

[2] Sato, Y., Ishikawa, S., Okubo, T., Abe, M., and Tamai, K., "Development of High Response Motor and Inverter System for the Nissan LEAF Electric Vehicle," SAE Technical Paper 201101-0350, 2011, doi:10.4271/2011-01-0350.

[3] Narumanchi, S., Mihalic, M., Kelly, K., and Eesley, G., "Thermal Interface Materials for Power Electronics Applications." Paper presented at the 11th Intersociety Conference on Thermal and Thermomechanical Phenomena in Electronic Systems, Orlando, Florida, May 28$31,2008$.

[4] "ASTM D5470-12, Standard Test Method for Thermal Transmission Properties of Thermally Conductive Electrical Insulation Materials," ASTM International, West Conshohocken, PA, 2012, DOI: 10.1520/D5470-12.

[5] Kirkup, L. Data Analysis with Excel: An Introduction for Physical Scientists. (Cambridge, MA: Cambridge University Press, 2002).

[6] Jeevanashankara, Madhusudana, C.V., and Kulkarni, M.B., "Thermal Contact Conductances of Metallic Contacts at Low Loads," Applied Energy 35:2 (1990): 151-164.

[7] Snaith, B., Probert, S.D., and O'Callaghan, P.W., "Thermal Resistances of Pressed Contacts," Applied Energy 22:1 (1986): 31-84.

[8] Dieck, R.H. Measurement Uncertainty: Methods and Applications. (Research Triangle Park, NC: ISA, 2007).

[9] Jih, E., Chen, K., Abraham, T., and Siddapureddy, V., "Thermal Management for the HEV Liquid-Cooled Electric Machine," in Vehicle Thermal Management Systems Conference \& Exposition, Nashville, TN, 2001, SAE Technical Paper 2001-01-1713, 2001, doi:10.4271/200101-1713.

[10] "ASTM A976-13, Standard Classification of Insulating Coatings for Electrical Steels by Composition, Relative Insulating Ability and Application." ASTM International, West Conshohocken, PA, 2013. 